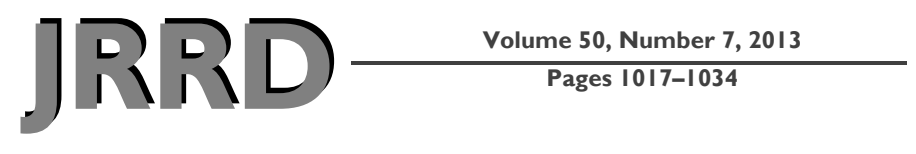

\title{
Evaluation of scooters using ANSI/RESNA standards
}

\author{
Ana E. Souza, PhD, PT; ${ }^{1-2}$ Jonathan L. Pearlman, PhD; ${ }^{1}$ Rosemarie Cooper, MPT; ${ }^{1-2}$ Annmarie Kelleher, \\ OTR/L, MS; ${ }^{1-2}$ Benjamin Gebrosky, BS; ${ }^{1}$ Rory A. Cooper, PhD ${ }^{1-2^{*}}$ \\ ${ }^{1}$ Human Engineering Research Laboratories, Department of Veterans Affairs, Pittsburgh, PA; ${ }^{2}$ Rehabilitation Science \\ and Technology Department, University of Pittsburgh, Pittsburgh, PA
}

\begin{abstract}
To date, only one research study has evaluated how scooters respond to static and dynamic stability. However, no other studies have evaluated how scooters respond to adverse conditions and how they perform in all standard tests. A selection of 12 three-wheeled scooters was tested according to American National Standards Institute/Rehabilitation Engineering and Assistive Technology Society of North America (ANSI/ RESNA) wheelchair standards. Scooter models included the Victory, Gogo, Golden Companion (GC) I, and GC II. Victory and GC II were the most stable scooters. The Gogo scooters were the least dynamically stable. Five scooters ( 3 Gogo, 1 GC I, 1 GC II) failed the environmental condition tests. All GC I and II scooters failed parts of the power and control system tests. All scooters passed static and impact tests; however, all Gogo scooters and one GC II scooter had structural or motor failure during durability tests. The scooter models' survival life ranged from 62,512 to $1,178,230$ cycles out of the 400,000 needed to pass the test. Tiller failures (typically tiller tube snapping) occurred with an average of $1,483 \mathrm{~N}$ force applied to the tiller structure. Our results indicate that these commercially available devices may not meet ANSI/RESNA standards. In addition, the tiller test should be conducted with scooters to further ensure their safety and durability and should use a test dummy with weight capacity according to the mobility device capacity.
\end{abstract}

Key words: ANSI/RESNA, durability tests, failure, fatigue life, mobility devices, scooters, stability, tiller test, wheelchairs, wheelchair standards.

\section{INTRODUCTION}

Recent statistics on growth among the older adult population from the Department of Health and Human Services' Administration of Aging show that the number of people aged 65 years or older increased from 35 million in 2000 to 40 million in 2010 . This population represents 12.9 percent of the U.S. population, which means one out of eight Americans are now older than 65 [1]. By 2030, there are expected to be about 72.1 million older persons in the United States, double the number in 2000. This anticipated increase in life expectancy may also cause a proportional growth in disability and, ultimately, an increased need for technical support for this population in performing daily activities [2]. Coupled with estimates that show that 75 to 90 percent of disabled older adults currently use some form of assistive technology for mobility [3], the possibility of 54-65 million people

Abbreviations: ANOVA $=$ analysis of variance, ANSI/ RESNA = American National Standards Institute/Rehabilitation Engineering and Assistive Technology Society of North America, $\mathrm{DME}=$ durable medical equipment, $\mathrm{EC}=$ equivalent cycle, $\mathrm{EPW}=$ electric powered wheelchair, $\mathrm{GC}=$ Golden Companion, $\mathrm{POV}=$ power operated vehicle, $\mathrm{SD}=$ standard deviation, VA = Department of Veterans Affairs.

*Address all correspondence to Rory A. Cooper, PhD; VAPHS-Human Engineering Research Laboratories, 6425 Penn Ave, Pittsburgh, PA 15206; 412-822-3700; fax: 412822-3699. Email: rcooper@pitt.edu

http://dx.doi.org/10.1682/JRRD.2011.03.0054 
requiring assistive technology by the year 2030 has farreaching implications. As the population ages, there is a noted increase in the demand for power mobility devices, including power wheelchairs and scooters [4-5]. The use of wheeled mobility devices in the United States has increased in the past decade, with a total number of nearly 4 million users, among whom 291,000 , or 7 percent, use power devices such as scooters [6]. A wide variety of wheeled mobility device options can be found on the market, including manual and power wheelchairs and scooters. With so many models to choose from, it is important for users to have access to objective information about their safety and durability so they can make an informed decision [7].

When clients come to a clinical setting looking for mobility devices, they usually look for scooters for two primary reasons: either they feel that these devices are more socially acceptable than other options or they may not have knowledge of the benefits of other types of mobility devices [8].

The prescription process should be client centered, where the clinician works together with the user to find the most appropriate mobility device. With so many options on the market, it can be a challenging process to choose the most appropriate mobility device. Depending on the reimbursement criteria of each client's insurance provider, clinicians may be required to select a mobility device that will not only be the most appropriate for the client's needs, but also fall within the client's insurance policy requirements. Currently, a number of different scooter models are available, and for this reason, it is important for clinicians, rehabilitation professionals, and their clients to know the features, performance, durability, and reliability of each device [9]. Research on the use of motorized scooters has shown that scooters might increase activity levels among people who have difficulty with ambulation and therefore increase their community participation [10]. Various organizations ensure that these devices are safe and durable, and most of these organizations rely on standardized testing methods. The American National Standards Institute/Rehabilitation Engineering and Assistive Technology Society of North America (ANSI/RESNA) have developed standard tests to assist clinicians and clients in evaluating and comparing different mobility device options and deciding the most appropriate device for the client's needs [11-12]. The ANSI/ RESNA standards allow an objective comparison of mobility devices within different test procedures [11-12].
Medicare requires many of the ANSI/RESNA standard tests to be conducted on all power operated vehicles (POVs) (e.g., scooters) to ensure the devices are safe, their performance meets target goals, and the performance and dimensions are disclosed to the end user and clinicians in a standardized format. Most tests can be conducted by the POV device manufacturer as long as they are conducted in a testing facility with equipment and personnel capable of testing according to ANSI/RESNA standards. Medicare requires some but not all the tests to be performed by an independent test laboratory before they will reimburse for the cost of the device, but the test reports are only rarely publicly available [3]. Both the absence of objective test reports and evidence of a high rate of breakdowns in the community (within a period of 6 mo, approximately $45 \%$ of users have complete repairs done to their wheelchair) have led to speculation that not all commercially available devices meet the standards [13]. Numerous research studies evaluating manual and power wheelchair compliance with the ANSI/RESNA standards [14-25] have substantiated these concerns. However, only one study to date has evaluated power wheelchairs' and scooters' compliance with ANSI/ RESNA standards specifically on static and dynamic stability (sections 1 and 2, respectively) [26]. Therefore, objective evaluation of scooters on all the relevant ANSI/ RESNA standards is needed to evaluate the performance, durability, and safety of these devices.

Medicare covers mobility devices under its durable medical equipment (DME) benefit program [27]. Medicare typically will not provide mobility devices that cannot be used in the home. Since scooters are devices that frequently do not maneuver in the home easily, this may cause manufacturers to try to make scooters with smaller bases and smaller turning radii, which may compromise user safety and stability when driving the scooter. Additionally, dynamic and static stability is likely to decrease for scooters that have narrower and/or shorter wheel bases. Table 1 shows basic information of selected scooter models found on the market. Models include both three and four wheels. Scooters with three wheels have one driving wheel in the front and two rear wheels in the back. Scooters with four wheels have two driving wheels in the front and two rear wheels in the back of the scooter.

Since one research study evaluated scooter compliance on two specific ANSI/RESNA tests, the primary purpose of our study was to evaluate scooter model compliance with all relevant ANSI/RESNA tests [26]. 
Table 1.

Brief description of popular scooters found on market. Included are scooters' manufacturer, model, weight capacity, and number of driving wheels.

\begin{tabular}{|c|c|c|c|}
\hline Manufacturer & Model & Weight Capacity (lb) & Base Options \\
\hline \multirow[t]{14}{*}{ Pride } & Gogo Ultra X & 260 & 3 or 4 wheels \\
\hline & Gogo Elite ${ }^{*}$ & 275 & 3 or 4 wheels \\
\hline & Gogo Elite Plus & 300 & 3 or 4 wheels \\
\hline & Travel Pro & 275 & 3 wheels \\
\hline & Revo & 300 & 3 or 4 wheels \\
\hline & Legend & 350 & 3 or 4 wheels \\
\hline & Victory 9 & 300 & 3 or 4 wheels \\
\hline & Victory 9PS & 300 & 3 wheels \\
\hline & Victory $10^{*}$ & 400 & 3 or 4 wheels \\
\hline & Celebrity X & 350 & 3 or 4 wheels \\
\hline & Pursuit & 400 & 4 wheels \\
\hline & Pursuit XL & 400 & 4 wheels \\
\hline & Wrangler & 400 & 4 wheels \\
\hline & Maxima & $400 / 500$ & 3 or 4 wheels \\
\hline \multirow[t]{7}{*}{ Golden Technologies } & Buzzaround Lite & 250 & 3 wheels \\
\hline & Buzzaround XL & 300 & 3 wheels \\
\hline & LiteRider & 300 & 3 wheels \\
\hline & Golden Companion I ${ }^{*}$ & 300 & 3 wheels \\
\hline & Golden Companion II ${ }^{*}$ & 350 & 3 wheels \\
\hline & Golden Companion GC440 & 350 & 4 wheels \\
\hline & Avenger & 500 & 4 wheels \\
\hline \multirow[t]{4}{*}{ Invacare } & Leo & 350 & 4 wheels \\
\hline & Lynx L-4 & 300 & 4 wheels \\
\hline & Lynx L-3 & 300 & 3 wheels \\
\hline & Lynx L-3X & 300 & 3 wheels \\
\hline \multirow[t]{3}{*}{ Hoveround Electric Mobility } & Transporter & 300 & 4 wheels \\
\hline & Transporter GL & 300 & 3 wheels \\
\hline & Bolero & 350 & 4 wheels \\
\hline
\end{tabular}

We conducted this compliance study to compare and contrast the performance of scooters on standardized tests. Further, we were interested in comparing the fatigue life of each scooter with the standard number of equivalent cycles (ECs). The ECs are the total number of equivalent durability cycles $(\mathrm{ECs}=$ [double-drum cycles $+30 *$ curbdrop cycles]) that the device endures prior to a class III failure, which is defined as "permanent damage, deformation, or failure that significantly affects the ability to operate the wheelchair" [28]. Finally, we were interested in the resistance of the tiller system to collapsing after a forward impact, which is a draft ANSI/RESNA test method.

\section{METHODS}

We conducted the ANSI/RESNA tests on 12 scooters of four different models from two scooter manufacturers. The scooters tested in our study were Victory $(n=3)$ (Pride Mobility Products; Exeter, Pennsylvania), Gogo ( $n=$ 3) (Pride Mobility Products), Golden Companion (GC) I $(n=3)$ (Golden Technologies; Old Forge, Pennsylvania), and GC II $(n=3)$ (Golden Technologies) (Figure 1). The scooters tested are the models most frequently prescribed nationwide at the Department of Veterans Affairs (VA) and also at the Center for Assistive Technology at the University of Pittsburgh Medical Center. 


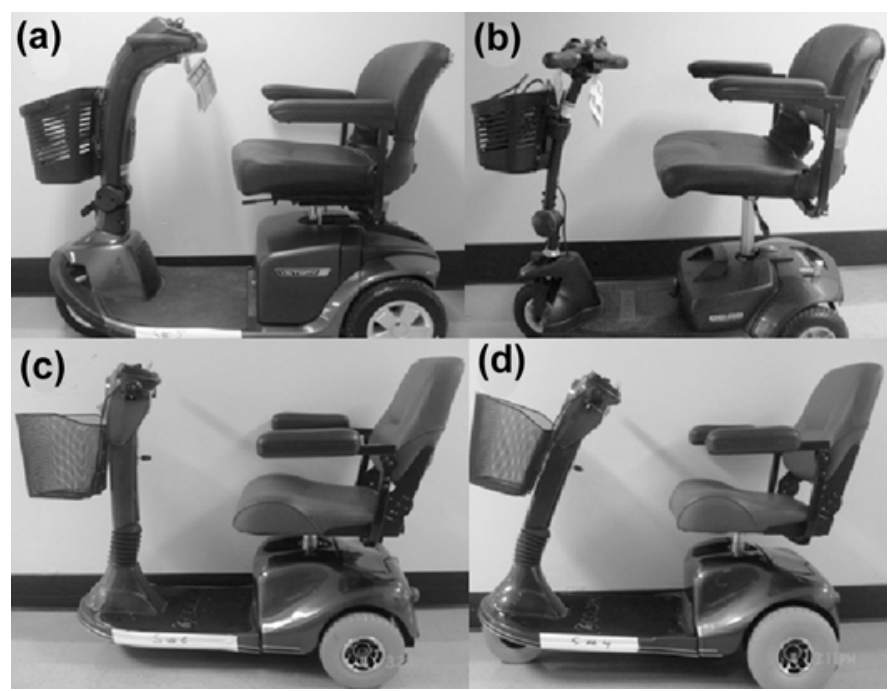

Figure 1.

Scooters tested: (a) Victory, (b) Gogo, (c) Golden Companion I, and (d) Golden Companion II.

The scooters were purchased through a third-party purchaser. Because of the cost and time invested in testing scooters, we chose to test three of each scooter model from the two manufactures (total $n=12$ ). The order of the scooters tested was random.

The ANSI/RESNA standard manual is arranged in such a way that each test is numbered and named in sections. All standard tests were conducted with each scooter in our study, with the exception of sections 16 and 21 (ignition of upholstery and electromagnetic compatibility, respectively), because our laboratory is not fully equipped to conduct these tests. The environment used was a test laboratory with an environmental chamber (climate tests), double-drum and curb-drop machines, ceiling lifts, and pendulums. The testing environment followed ANSI/RESNA specifications. Incline tests and tennis court tests were conducted outside the research laboratory.

The tests conducted were static and dynamic stability (sections 1 and 2, respectively); effectiveness of brakes (section 3); energy consumption (section 4); maximum speed, acceleration, and retardation (deceleration) (section 6); climatic testing (section 9); impact and fatigue tests (section 8); power and control systems (section 14); and the tiller test (added by researchers). All the tests were performed as specified in the 1998 edition of the ANSI/RESNA testing standards, which was the current edition when these tests were completed. In addition to the standard tests, we conducted a test on the scooters' tillers to determine the forward-directed load on the tiller that would cause it to deform and then fail.

\section{Tests}

\section{Static Stability (Section 1)}

The static stability test was performed by placing the scooter with a $100 \mathrm{~kg}$ test dummy on a test ramp and changing the inclination of the test ramp until the angle was found at which the scooter tipped (Figure 2). The angles were recorded for the scooter setup with the most and least stable configurations in the following directions: forward (wheels unlocked and locked), rearward (wheels unlocked and locked), sideways (left and right sides down slope), and on the antitippers (either front or back). For the static stability test, the scooters were tested with and without their mechanical brakes on. A total of 14 measurements were recorded.

\section{Dynamic Stability (Section 2)}

Dynamic stability was performed by evaluating the response of the scooter to dynamic tasks while it traveled on flat surfaces at $0^{\circ}, 3^{\circ}, 6^{\circ}$, and $10^{\circ}$ slopes. For each scooter, 31 tasks were performed, including starting and stopping; traveling upward and downward while turning; and traveling up and down a step transition of 12, 25, and $50 \mathrm{~mm}$. For all cases, a human operator maneuvered the scooter. All trials were performed at maximum speed.

Scooter responses were coded with scores ranging from 0 to 4 , where-

- 4 = "At least 1 uphill wheel remains on the test plane."

- 3 = "Lifted all uphill wheels temporarily and anti-tippers did not contact the test plane."

- 2 = "Transient tip when going uphill and the anti tippers touched the test plane."

- 1 = "Uphill wheels lift off and the scooter remained on the anti-tipper devices."

- $0=$ "The scooter tipped over completely." [11]

\section{Effectiveness of Brakes (Section 3)}

Effectiveness of brakes testing was performed with a person with weight equivalent to $100 \mathrm{~kg}$ sitting in the scooter and driving at its maximum speed. The person's weight was determined by the standards according to the equivalent weight of a 95th percentile American man. Since the testing technician weighed less than the 
(a)

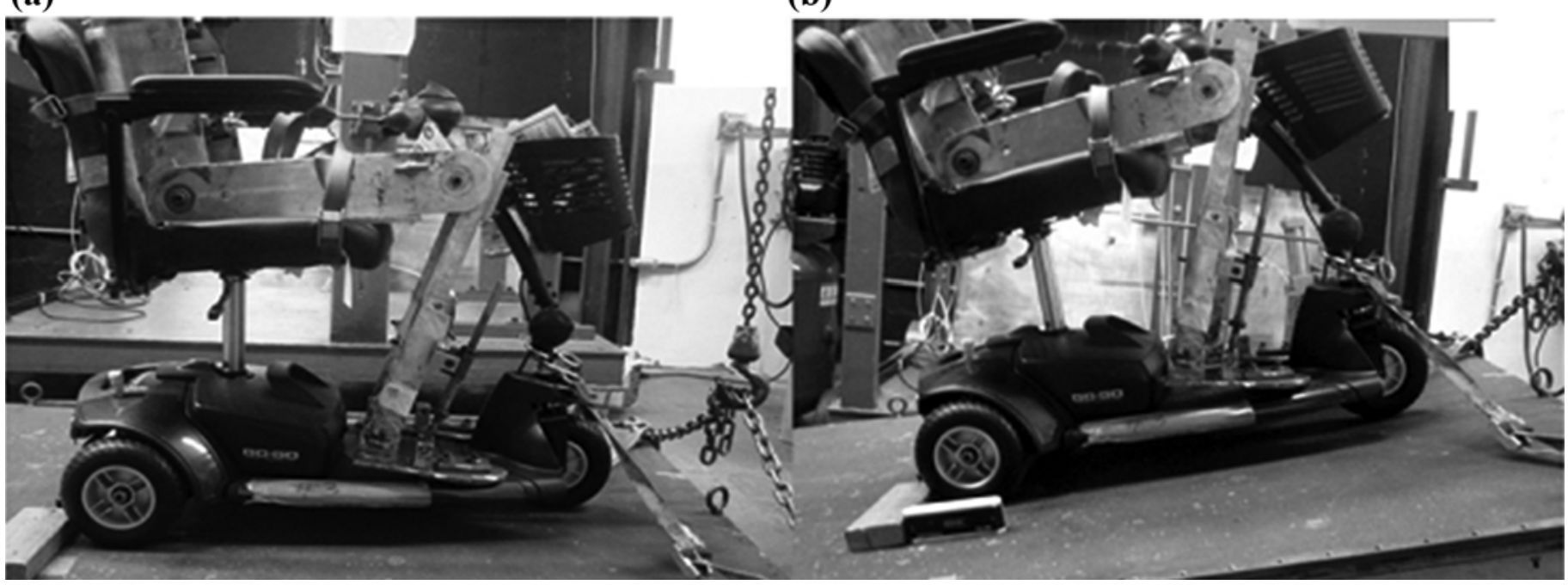

Figure 2.

Forward stability test with scooter in least stable configurations and without mechanical brakes on. All rearward stability tests were conducted with least stable configuration. (a) Scooter was placed facing uphill and secured with straps from tipping backward completely. (b) Angle was recorded when front wheels started to lose contact with testing plane.

required $100 \mathrm{~kg}$, weight was added under the operator on the seat. The braking distance was recorded by measuring the distance from the point where the braking system was activated to the point where the scooter came to a complete stop. This test was also performed on $3^{\circ}, 6^{\circ}$, and $10^{\circ}$ test planes in both forward and rearward directions. The tester applied the brakes to the scooter three ways: throttle release, throttle reverse, and key-off. While testing the effectiveness of brakes on a $10^{\circ}$ slope, scooters tended to tip completely; therefore, for safety reasons, some scooters were not tested on a $10^{\circ}$ slope because of the high risks of tipping over completely and causing injuries to the person operating the scooter.

\section{Energy Consumption (Section 4)}

The theoretical range that each scooter could travel before it ran out of battery was calculated by the energy consumption that occurred over a measured distance. More specifically, by measuring the depletion of a fully charged battery with a known capacity while traveling a known distance, the theoretical range could be calculated by Equation (1):

$$
R=\frac{C \times D}{E \times 100},
$$

where $\mathrm{R}=$ theoretical range (in kilometers), $\mathrm{C}=$ battery capacity (in ampere-hours), D = known distance (in meters), and $\mathrm{E}=$ ampere-hours.

\section{Maximum Speed, Acceleration, and Retardation (Deceleration) (Section 6)}

Speed, acceleration, and retardation (deceleration) were measured with a $100 \mathrm{~kg}$ person controlling the scooter. The testing technician on the scooter was asked to accelerate the scooter to its maximum speed on a flat surface located outdoors. Overall acceleration was determined from a stop to the maximum speed, and maximum acceleration was identified and reported from these trials. Overall and maximum retardation (deceleration) were recorded from the point of braking to the point where the scooter came to a complete stop under three conditions: throttle release, throttle reverse, and key-off. As determined by the standards and for the drivers' safety, these tests were conducted only at $0^{\circ}, 3^{\circ}$, and $6^{\circ}$ slopes in a forward direction.

\section{Climatic Testing (Section 9)}

Climatic testing was performed by exposing the scooters to adverse environmental behaviors including rain conditions, cold operating conditions, hot operating conditions, cold storage conditions, and hot storage 
conditions. The rain test entailed spraying the scooter with a stream of water for 10 minutes. The cold operating test was performed by placing the scooter in an environmental chamber at a temperature of $-25^{\circ} \mathrm{C}+2^{\circ} \mathrm{C} /-5^{\circ} \mathrm{C}$ for 3 hours. The hot operating test was performed by placing the scooter in an environmental chamber for 3 hours at a temperature of $50^{\circ} \mathrm{C}+5^{\circ} \mathrm{C} /-2^{\circ} \mathrm{C}$. The last two tests (hot and cold storages tests) were conducted by placing the scooters in an environmental chamber with temperatures of $65^{\circ} \mathrm{C} \pm 5^{\circ} \mathrm{C}$ and $-40^{\circ} \mathrm{C} \pm 5^{\circ} \mathrm{C}$, respectively, for 5 hours. Functional tests were performed 1 hour after removing the scooters from the environmental chamber. For the functional testing, each scooter was driven through a test track and any adverse responses were reported as failure per the standards. The adverse behaviors and events that could have caused the scooter to fail the functional test included (1) any dangerous behaviors while the tester was driving, (2) the time taken to drive around the test track being longer than $60 \mathrm{sec}$ onds, (3) failure of the scooter to stop, and (4) failure of the scooter to remain stationary when the control device was released.

\section{Static, Impact, and Fatigue Tests (Section 8)}

Static, impact, and fatigue tests were performed by applying static and impact loading conditions to parts of the scooter (armrests, footrests, wheels, shrouding) and by testing the fatigue life of the whole scooter. Static tests were performed with the scooter on the horizontal test plane as specific loads were applied to various parts of the scooter. The loads/forces applied are specified in the standard according to the part tested; the forces ranged from 15 to 2,000 N. Impact tests were performed with a pendulum used to strike parts of the scooter to which impacts could occur during a user's daily routine: on the backrest, footrest structures, and antitippers and shrouds. All forces and angles applied to the scooters were specified by the standards to mimic the possible impacts and static stresses that a scooter would be regularly exposed to. Fatigue life (or durability) was tested using doubledrum and curb-drop testing machines. Results of these tests were based on whether the scooters passed or failed each test; for the fatigue testing, the scooter passed if it endured 200,000 cycles on the double-drum and 6,666 curb-drop cycles (which is equivalent to 3-5 years of use). There are three classifications of failures. Class I is defined as failures for which minor adjustments or repairs may be accomplished by the wheelchair/scooter user or an untrained assistant, such as tightening a loose screw or bolt. Class II failures encompass minor repairs that can be accomplished by a repair technician and include repairing or replacing flat tires or making complex adjustments (e.g., adjust a wheel). Class III failures occur when permanent damage, deformation, or failure significantly impairs operability or safety of the wheelchair/scooter. To determine their exact survival life, we repeated the fatigue test on scooters that passed the initial 200,000 double-drum cycles and/or 6,666 curb-drop cycles until the scooter failed. To compute the survival life, we calculated the scooters' ECs as was previously defined.

Scooters that exceeded an EC score of 400,000 cycles were recorded as passing the minimum requirements of the ANSI/RESNA standards. To evaluate the cost effectiveness (value) of scooters, we obtained the value of each scooter by normalizing the number of ECs by the manufacturer's suggested retail price (unit of value = cycles per dollar). For additional information, please refer to ANSI/RESNA wheelchair standards [11-12].

\section{Power and Control Systems (Section 14)}

Power and control system tests set minimum requirements for the protection of the scooter not only during normal use but also when scooters show adverse behaviors due to user or maintenance errors. All adverse behaviors (e.g., reversing the polarity of batteries) that are potentially dangerous are reported. These tests are applicable to electrically powered devices intended to be used indoors and outdoors among people with mobility difficulties whose mass does not exceed $100 \mathrm{~kg}$, according to the standards.

\section{Tiller Test}

After all scooters were tested until failure in section 8 , we tested the strength of each scooter tiller in order to identify the forward-directed load at which the tiller would move and, ultimately, collapse. This test was recently proposed by the ANSI/RESNA standards committee. To conduct the test, the scooters were restrained on the double drum to prevent them from moving during the test, leaving the tiller free (Figure 3). They were restrained to prevent the rear end of the scooters from lifting as a result of the force being applied to the tiller. After the scooters were secure, a pulling apparatus that included a method of indicating the force being used $( \pm 2,273 \mathrm{~N})$ was attached to the tiller handles. The pulling apparatus then pulled the tiller parallel to ground plane toward the front of the scooter. We recorded the maximum force applied to the tiller at the time permanent deflection of the tiller occurred; we then recorded the force at which 


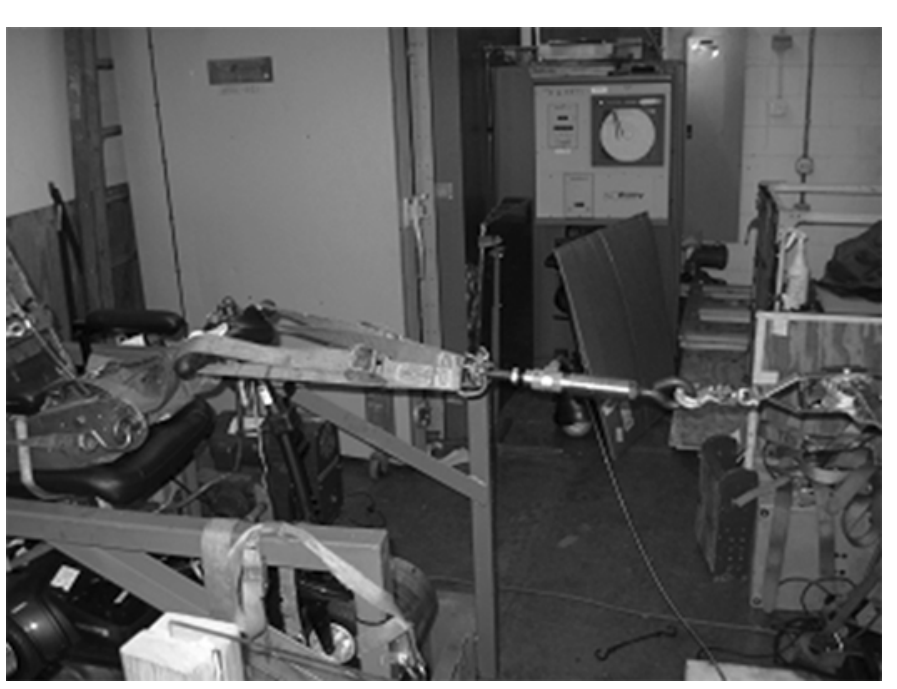

Figure 3.

Setup of scooters for tiller test.

the tiller components broke completely (e.g., tiller bar permanently detached from the scooter).

\section{Data Analysis}

Selection of statistical analysis (parametric or nonparametric) was based on data normalcy. Statistical analyses were conducted on the results of sections 1 to 4 of the ANSI/RESNA standards. For normally distributed data, analysis of variance (ANOVA) was performed to evaluate each scooter (independent variable) within continuous variables such as static and dynamic test, effectiveness of brakes, and energy consumption (dependent variables). A Kruskal-Wallis one-way ANOVA was performed when data were not normally distributed (nonparametric test for independent samples). The Mann-Whitney $U$ test was used to perform post hoc analysis with pairwise comparisons of scooter groups. All statistical tests were performed using PASW Statistics 18 software (SPSS Inc; Chicago, Illinois). An alpha level of 0.05 was set a priori.

\section{RESULTS}

\section{Static Stability and Dynamic Stability}

The results of static stability are shown in Table 2 for the least stable setup of each scooter model. Scooters that were more stable had a higher reported angle. There was no statistically significant difference among the four models in forward and lateral stability tests. Statistically significant differences were observed on rear stability with wheels locked $(p=0.02)$ and wheels unlocked $(p=$ $0.02)$ among scooters, where the Victory scooters were the more stable models with wheels locked and unlocked; in addition, they were most stable during the antitippers tests, followed by the Gogo scooters. Statistically significant results were observed $(p=0.04)$ on the Victory and Gogo scooters during lateral tests on sideways right position. Overall, the GC I and II scooters were the most stable on lateral tests. Post hoc analysis (Tukey post hoc) results (Table 2 superscript) show grouping among the scooters' tipping angle direction; the groups are displayed from lowest tipping angle (most stable condition) to highest tipping angle (least stable condition).

The dynamic stability test rated the scooters' response while traveling on level surfaces of $0^{\circ}, 3^{\circ}, 6^{\circ}$, and $10^{\circ}$ slopes. Results of the dynamic stability tests were not statistically significantly different among the scooter models. Scores that were not equally scored (e.g., all values $=4$ ) are presented in Table 3 with their mean

Table 2.

Static stability and comparison.

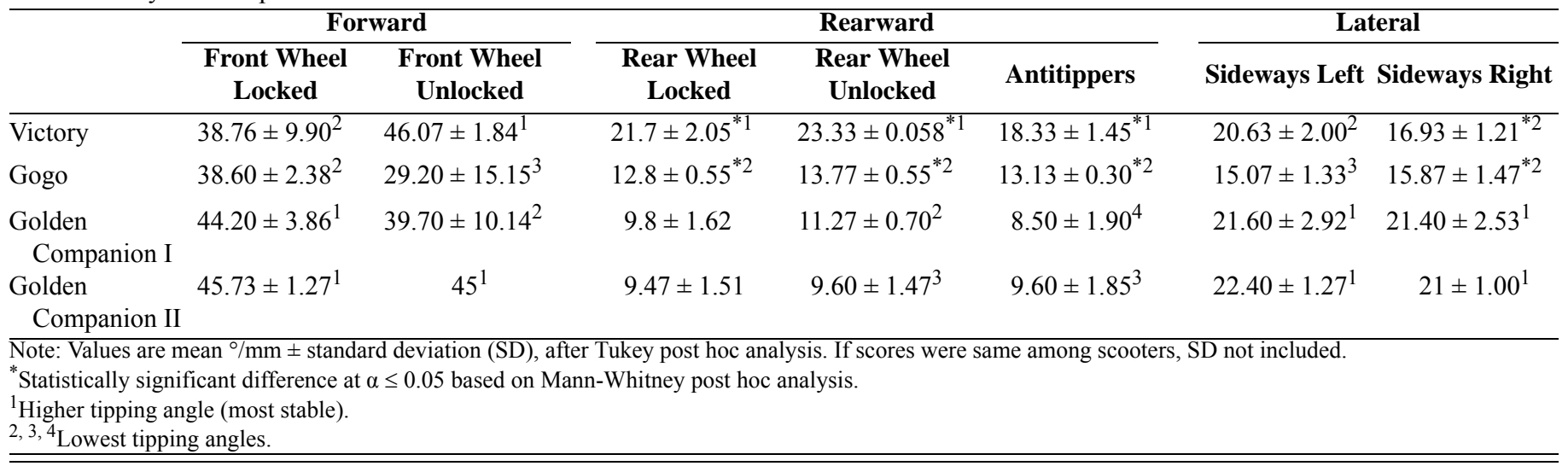


JRRD, Volume 50, Number 7, 2013

Table 3.

Dynamic stability scores.

\begin{tabular}{|c|c|c|c|c|}
\hline \multirow{2}{*}{ Stability Test } & \multicolumn{4}{|c|}{ Scooter } \\
\hline & Victory & Gogo & Golden Companion I & Golden Companion II \\
\hline \multicolumn{5}{|l|}{ RUH(sta) } \\
\hline $6^{\circ}$ & 4 & 4 & 4 & 4 \\
\hline $10^{\circ}$ & 4 & 4 & 4 & 4 \\
\hline $6^{\circ}$ & 4 & 4 & 4 & 4 \\
\hline $10^{\circ}$ & 4 & $2.67 \pm 2.31$ & 4 & $3.67 \pm 0.58$ \\
\hline \multicolumn{5}{|l|}{ RDH(br) } \\
\hline $0^{\circ}$ & 4 & 4 & 4 & 4 \\
\hline \multicolumn{5}{|l|}{ F(br) } \\
\hline $0^{\circ}$ & 4 & 4 & 4 & 4 \\
\hline $3^{\circ}$ & 4 & 4 & 4 & $2.67 \pm 2.31$ \\
\hline $6^{\circ}$ & 4 & 4 & 4 & 4 \\
\hline $10^{\circ}$ & 4 & $2.67 \pm 2.31$ & 4 & $3.67 \pm 0.58$ \\
\hline \multicolumn{5}{|l|}{$\mathbf{F}(\mathbf{1})$} \\
\hline $3^{\circ}$ & 4 & 4 & 4 & 4 \\
\hline $6^{\circ}$ & 4 & 4 & 4 & 4 \\
\hline $10^{\circ}$ & 4 & $2.70 \pm 2.31$ & 4 & $2.70 \pm 2.31$ \\
\hline $25^{\circ}$ & 4 & 4 & 4 & 4 \\
\hline $50^{\circ}$ & $3.67 \pm 0.58$ & 4 & $3.67 \pm 0.58$ & 4 \\
\hline \multicolumn{5}{|l|}{ F-TRAN } \\
\hline $12^{\circ}$ & 4 & 4 & 4 & 4 \\
\hline $25^{\circ}$ & 4 & 4 & 4 & 4 \\
\hline $50^{\circ}$ & 4 & 4 & 4 & $3.70 \pm 0.60$ \\
\hline \multicolumn{5}{|l|}{ LAT-TRAN } \\
\hline $12^{\circ}$ & 4 & 4 & 4 & 4 \\
\hline $25^{\circ}$ & 4 & 4 & 4 & 4 \\
\hline $50^{\circ}$ & 4 & $3.30 \pm 0.60$ & 4 & $3.70 \pm 0.60$ \\
\hline
\end{tabular}

Note: Scores ranged from $0-4$.

$\mathrm{F}(\mathrm{br})=$ forward braking stability when traveling forward, $\mathrm{F}(\mathrm{l})=$ forward braking stability when traveling from sloped surface to level surface, F-TRAN $=$ forward stability when traveling down step transition, LAT-TRAN = lateral stability when 1 side of scooter travels down step transition, LAT-TRN $=$ lateral stability when turning on downhill slope, $\mathrm{RDH}(\mathrm{br})=$ rearward braking stability when traveling backward down slope, R-TRAN = rearward stability when traveling up step transition, $\mathrm{RUH}(\mathrm{br})=$ rearward stability when braking after traveling forward on uphill slope, $\mathrm{RUH}(\mathrm{sta})=$ rearward stability when starting uphill on slope. 
and standard deviation (SD) values. Overall, the Gogo and GC I and II scooters more frequently tipped. The Victory scooters were the most stable in most positions, except during rearward stability when traveling up a step transition (mean $\pm \mathrm{SD}=3.67 \pm 0.58$ ).

\section{Effectiveness of Brakes}

This test was performed to test effectiveness of brakes on $0^{\circ}, 3^{\circ}, 6^{\circ}$, and $10^{\circ}$ test planes in both the forward and rearward directions (Table 4). A Kruskal-Wallis test was conducted to evaluate differences on braking distances among scooter models. Results showed that most results on the horizontal condition and $10^{\circ}$ slopes were statistically significant different among scooters $(p<$ 0.05 ). No statistically significant difference was observed among scooters tested on $3^{\circ}$ and $6^{\circ}$ slopes. Considering the variability of the data, we observed that, for most $0^{\circ}, 3^{\circ}$ and $6^{\circ}$ test planes, the GC II scooters had the highest braking distances, followed by the Victory scooters. The Gogo scooters had higher braking distances on the $10^{\circ}$ testing plane. The Gogo scooters had lower braking distances on most testing planes, except the $10^{\circ}$ testing plane.

Table 4.

Effectiveness of brakes.

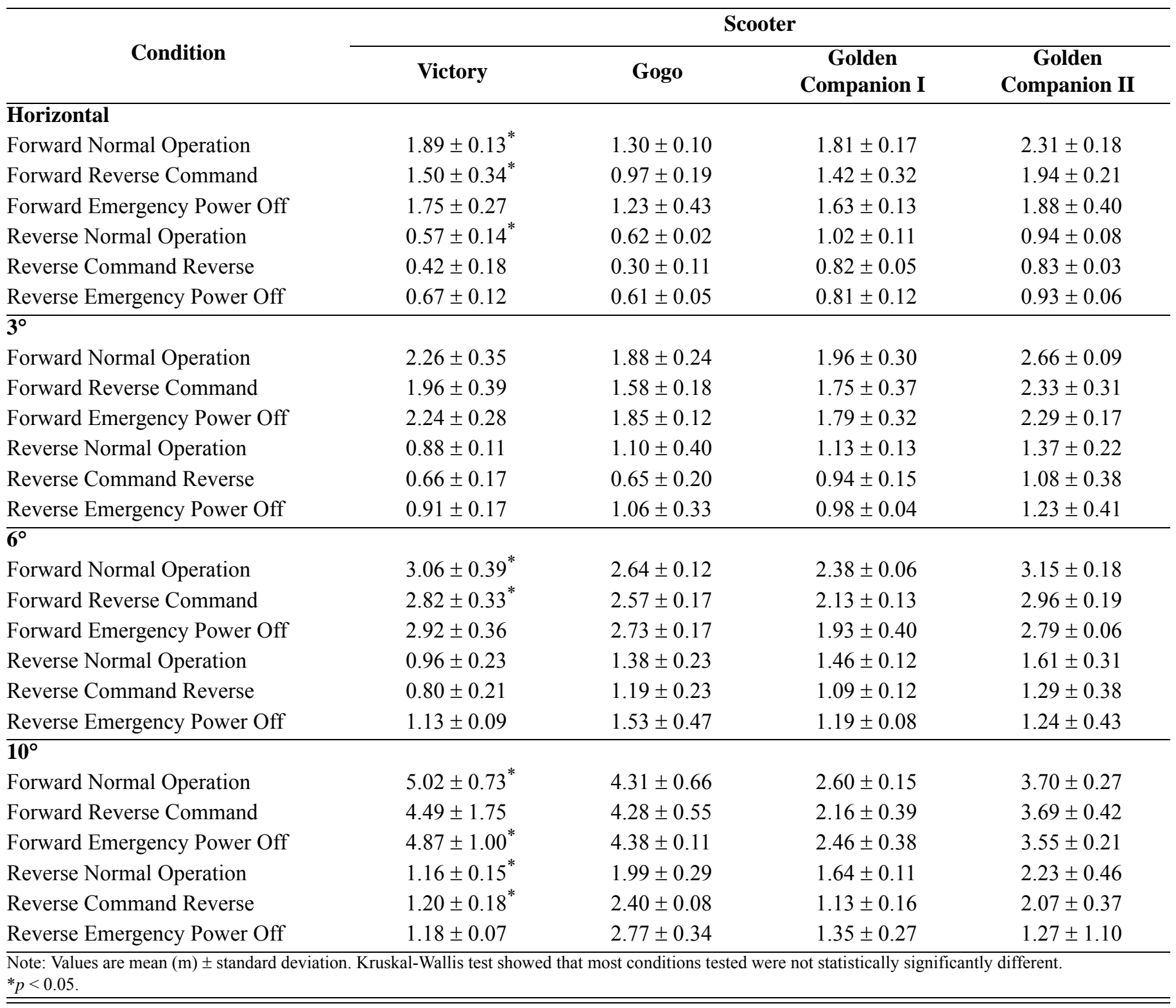




\section{Energy Consumption Test}

No statistically significant difference was observed among the scooters. The mean \pm SD values showed that the Victory and GC I scooters had higher theoretical ranges $(30.33 \pm 12.74$ and $30.00 \pm 15.71$, respectively), followed by the GC II and Gogo scooters $(24.67 \pm 3.05$ and $17.67 \pm 0.58$, respectively).

\section{Maximum Speed, Acceleration, and Retardation (Deceleration) Tests}

Although no statistical significance was observed, on the horizontal plane the GC II scooters had higher speeds in the forward direction, followed by the Victory scooters. Victory scooters showed higher speeds going downhill on $3^{\circ}$ and $6^{\circ}$ ramps. The Gogo scooters showed higher rearward speeds, followed by the GC II scooters (Table 5). Acceleration results were similar among the scooters, with higher overall and maximum acceleration from Gogo scooters (Table 6). The GC I scooter had the lowest overall retardation (deceleration) and the Victory had the highest overall retardation (deceleration). The GC II had the lowest overall maximum retardation (deceleration) and the Gogo had the highest overall maximum retardation (deceleration). The GC I had the lowest overall emergency reverse retardation (deceleration) and the Victory had the highest overall emergency reverse retardation (deceleration). Maximum retardation (deceleration) during emergency reverse was the highest for the Gogo and lowest for the GC II. Overall emergency power off retardation (deceleration) was lowest for the Gogo and highest for the Victory. The GC II had the lowest maximum emergency power-off retardation (deceleration) and the Gogo had the highest maximum emergency power-off retardation (deceleration).

\section{Climate Testing}

All Gogo scooters and one GC I scooter failed the rain condition test and one GC II failed the hot storage condition test $\left(<65^{\circ} \mathrm{C}\right)$. The Victory scooters passed all the climate test conditions. The scooters that failed the rain condition test started to work again after we opened all the controller boxes and dried all the water retained. The GC II that failed the hot storage condition test started working again 1 hour after the test. On average, each

Table 5.

Average maximum speed in forward and reverse directions.

\begin{tabular}{|c|c|c|c|c|c|c|}
\hline \multirow[b]{2}{*}{ Scooter } & \multicolumn{6}{|c|}{ Maximum Speed } \\
\hline & $\begin{array}{c}\text { Forward } \\
\text { Horizontal }\end{array}$ & $\begin{array}{c}\text { Uphill } \\
3^{\circ} \text { Ramp }\end{array}$ & $\begin{array}{c}\text { Uphill } \\
6^{\circ} \text { Ramp }\end{array}$ & $\begin{array}{l}\text { Forward } \\
\text { Downhill } \\
3^{\circ} \text { Ramp }\end{array}$ & $\begin{array}{l}\text { Forward } \\
\text { Downhill } \\
6^{\circ} \text { Ramp }\end{array}$ & $\begin{array}{l}\text { Rearward } \\
\text { Horizontal }\end{array}$ \\
\hline Victory & $2.46 \pm 0.23$ & $2.27 \pm 0.51$ & $1.98 \pm 0.18$ & $2.71 \pm 0.34$ & $2.88 \pm 0.07$ & $0.93 \pm 0.01$ \\
\hline Gogo & $1.91 \pm 0.18$ & $1.65 \pm 0.38$ & $1.51 \pm 0.68$ & $2.01 \pm 0.08$ & $2.37 \pm 0.21$ & $1.25 \pm 0.47$ \\
\hline Golden Companion I & $2.07 \pm 0.01$ & $1.79 \pm 0.13$ & $1.50 \pm 0.07$ & $2.31 \pm 0.06$ & $2.45 \pm 0.09$ & $1.04 \pm 0.01$ \\
\hline
\end{tabular}

Table 6.

Acceleration and retardation (deceleration) results.

\begin{tabular}{|c|c|c|c|c|c|c|c|c|}
\hline \multirow[b]{2}{*}{ Scooter } & \multicolumn{2}{|c|}{ Acceleration } & \multicolumn{6}{|c|}{ Retardation (deceleration) } \\
\hline & Overall & Maximum & Overall & Maximum & $\begin{array}{c}\text { Overall } \\
\text { Emergency } \\
\text { Reverse }\end{array}$ & $\begin{array}{c}\text { Maximum } \\
\text { Emergency } \\
\text { Reverse }\end{array}$ & $\begin{array}{c}\text { Overall } \\
\text { Emergency } \\
\text { Power Off }\end{array}$ & $\begin{array}{c}\text { Maximum } \\
\text { Emergency } \\
\text { Power Off }\end{array}$ \\
\hline Gogo & $0.79 \pm 0.04$ & $1.91 \pm 0.02$ & $1.29 \pm 0.44$ & $-2.29 \pm 0.22$ & $1.82 \pm 0.11$ & $-2.03 \pm 0.75$ & $1.57 \pm 0.05$ & $-2.24 \pm 0.09$ \\
\hline $\begin{array}{l}\text { Golden } \\
\text { Companion I }\end{array}$ & $0.54 \pm 0.06$ & $1.84 \pm 0.34$ & $0.91 \pm 0.33$ & $-3.01 \pm 0.37$ & $0.97 \pm 0.41$ & $-3.22 \pm 0.13$ & $0.99 \pm 0.24$ & $-3.64 \pm 0.45$ \\
\hline
\end{tabular}


Gogo scooter took around 3-6 weeks to dry completely and start functioning again. The GC I scooter started working again after 1 week. Abnormal responses observed on these scooters were a whistling sound was coming from the controller box, the scooter would not move, and the scooter would not turn off.

\section{Static, Impact, and Fatigue Tests}

All scooters passed the impact and static tests. Conversely, fatigue test results varied among scooter models. All Victory and GC I scooters passed the fatigue tests. The fatigue tests were stopped once the scooters exhibited a class III failure. All the Gogo scooters failed during the double-drum tests, and consequently, they were not tested on the curb-drop test. All the Gogo scooters had motor failures and none reached even half of the 200,000 cycles on the double-drum test. The maximum number of cycles achieved was 87,922 cycles. One GC II had structure failure, with a seat structure breaking during the curb-drop test after 1,034 cycles (Figures 4-5). The other two GC II scooters had motor failures during the double-drum test, reaching a maximum of 50,162 and 173,803 cycles. Average ECs were 1,178,230 cycles for Victory, 62,512 cycles for Gogo, 634,870 cycles for GC I, and 151,662 cycles for GC II (Figures 6-7). Cost effectiveness differed among scooter models. Values ranged from 41 to 527 cycles/\$ (Table 7).

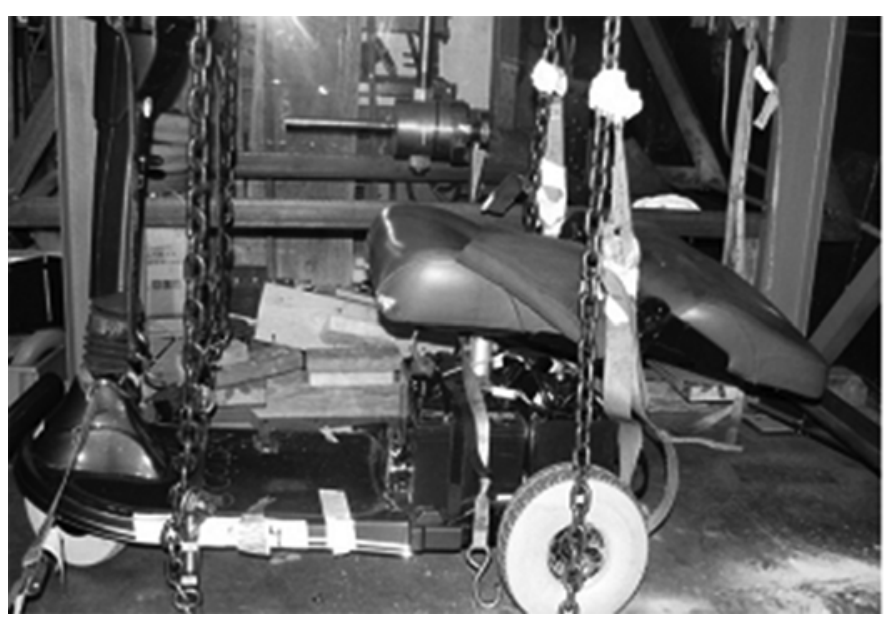

Figure 4.

Golden Companion II after double-drum test with seat frame broken.

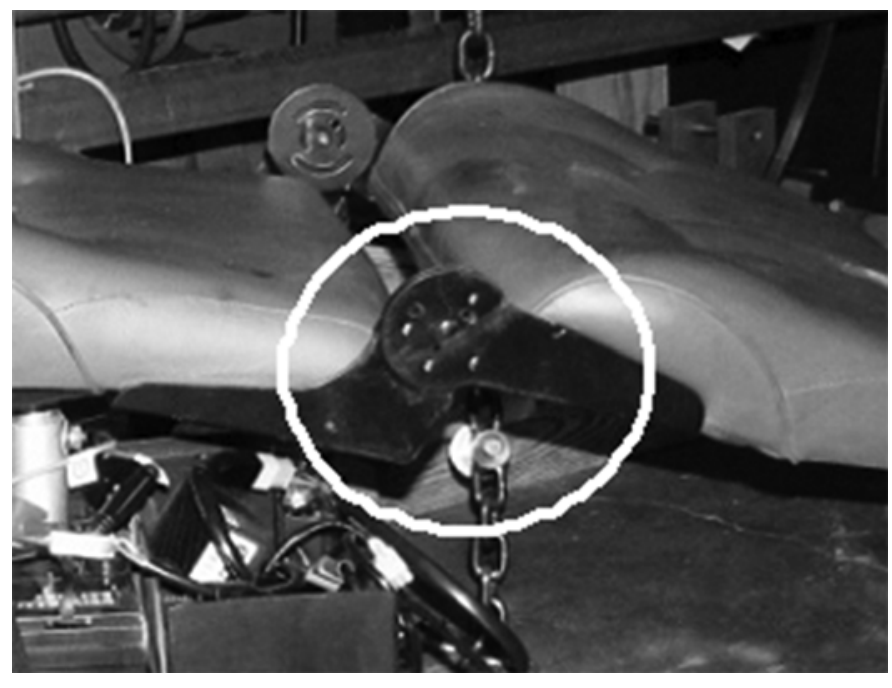

Figure 5.

Close view of seat frame broken after double-drum test.

\section{Tiller Test}

Results from this test showed that an average of $1,483 \pm 512 \mathrm{~N}$ was needed to break the tiller. The Victory scooters were more resistant than the other scooters, with an average breaking force of $1,578 \pm 179 \mathrm{~N}$, followed by the Gogo, with an average breaking force of 1,466 \pm $422 \mathrm{~N}$. The tiller of the GC II scooters broke with an

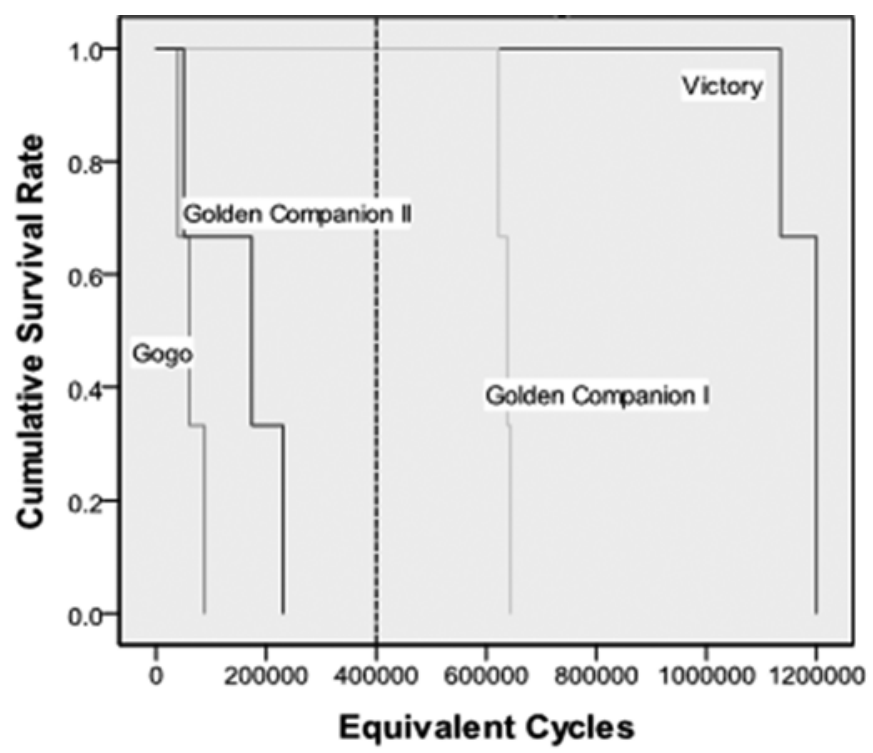

Figure 6.

Survival curve for scooters. Broken vertical line marks 400,000 equivalent cycles, which indicates passing of durability test. 


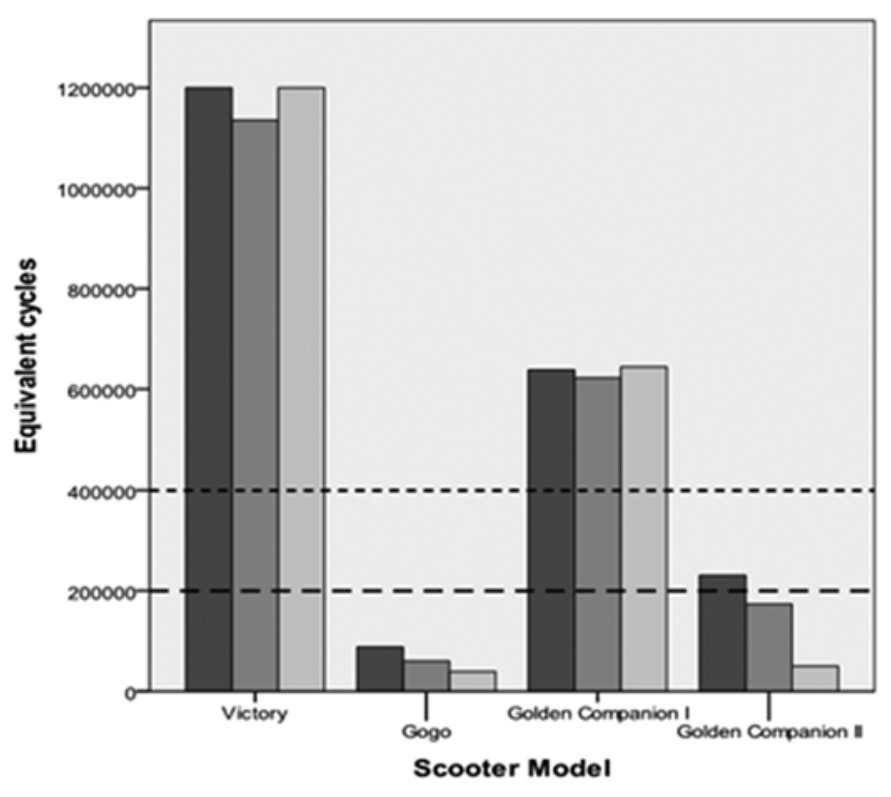

Figure 7.

Equivalent cycles of each scooter in fatigue test. Wide dashed line represents 200,000 cycles required to pass double-drum test. Narrow dashed line at 400,000 cycles indicates minimum request in American National Standards Institute/Rehabilitation Engineering and Assistive Technology Society of North America standards.

average force of $1,495 \pm 678 \mathrm{~N}$ and the GC I scooters with an average force of 1,394 $\pm 865 \mathrm{~N}$ (Table 8). In general, the mode of failure was snapping of the tiller tube $(n=$ $10)$ or failure of the adjustment strut mounting bolt $(n=$ 2) located in the pivot of the tiller. When the failure was on the adjustment strut, the tiller tube would not separate completely; however, the scooter still became unusable (Figure 8). Failures where the tiller did not separate completely from the scooter $(n=2)$ occurred with one Gogo scooter and one GC I scooter. All Victory and GC

Table 7.

Equivalent cycles (ECs) and value.

\begin{tabular}{lcc}
\hline & \multicolumn{1}{c}{ EC (cycles) } & Value (cycles/\$) \\
\hline Victory & $1,178,230 \pm 37,602$ & $527 \pm 17$ \\
Gogo & $62,512 \pm 24,430$ & $41 \pm 16$ \\
Golden & $634,870 \pm 11,316$ & $232 \pm 4$ \\
$\quad$ Companion I & $151,662 \pm 92,439$ & $54 \pm 33$ \\
Golden & \\
$\quad$ Companion II & & \\
\hline Note: Values are mean \pm standard deviation. & \\
\hline
\end{tabular}

Table 8.

Forces values at tiller failure.

\begin{tabular}{lc}
\hline & Force (N) \\
\hline Victory & $1,578 \pm 179$ \\
Gogo & $1,466 \pm 422$ \\
Golden Companion I & $1,394 \pm 865$ \\
Golden Companion II & $1,495 \pm 678$ \\
\hline Note: Values are mean (N) \pm standard deviation. & \\
\hline \hline
\end{tabular}

II scooters and the two remaining Gogo and GC I scooters had tillers that separated completely from the scooter (Figure 8).

\section{Power and Control Systems}

The results of this section varied among the manufacturers. Given that this section comprises a large number of tests, we are only reporting abnormal responses and failed tests. Responses were rated as pass/fail according to the standards. The Victory scooters passed all the tests included in this section. On the other hand, the Gogo scooters failed the test for safety when charging batteries. In this test, for user safety, the scooter should not move while charging the battery; however, all the Gogo scooters moved freely while plugged into the charger. This adverse response concerns us because a distracted user might forget that the scooter is being charged and start driving, which could lead to involvement in an accident. The GC I and II scooters failed three electrical systems

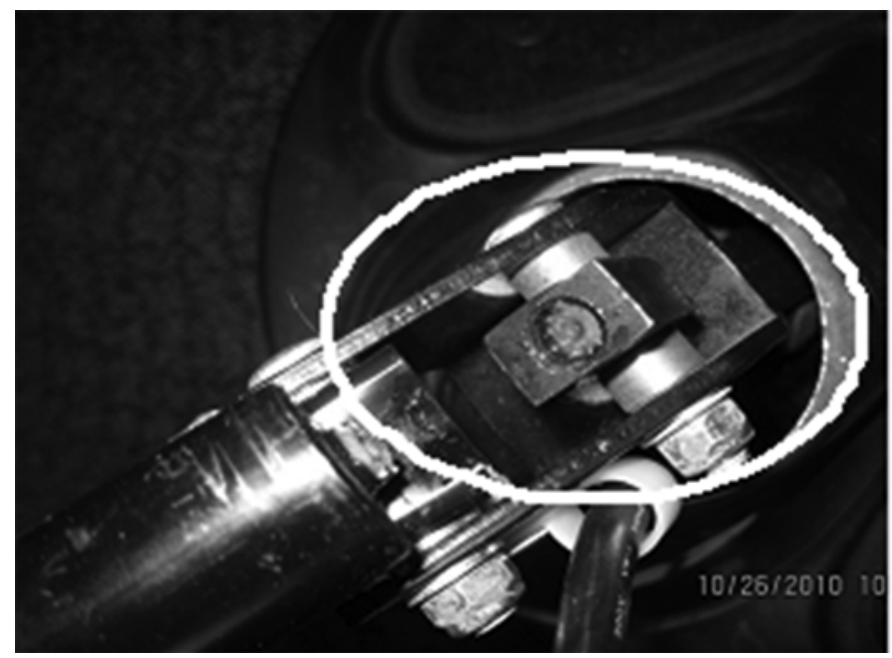

Figure 8.

Close view of failure in tiller pivot. Bolt holding adjustment strut to tiller assembly snapped. 
tests. These failures included missing battery connection and circuit protection diagram; orange and red, instead of black and red, wires connecting the batteries; and missing fuses and connectors. Interestingly, the GC I contained no labeling to indicate the battery's rated capacity. No other adverse responses were observed with the scooters tested.

\section{DISCUSSION}

\section{Static Stability}

The static stability tests were conducted with the scooters configured in the least stable condition. It was expected that scooters with bigger wheel bases and overall larger dimensions would be more stable than scooters with smaller wheel bases. The Victory scooters were more stable in most directions. This could have been due to their overall larger dimensions, higher scooter mass, or the outer position of antitippers. The most stable scooters in front wheel lock and sideways were the GC I and II. Those scooters also have wider bases and larger dimensions, differing only in their wheel dimensions. The Gogo scooters were the least stable scooters in all directions, likely because of their smaller bases, smaller wheel diameters, and overall smaller dimensions. The characteristics that determined scooter stability were based on the angles at which the scooter wheels (front or rear, depending on the test direction) would lose contact with the testing surface; therefore, the scooters with higher stability would benefit users in the different situations regularly encountered while driving their scooters over different terrains and surfaces.

\section{Dynamic Stability}

Dynamic stability results varied between models, and the Victory was the overall most stable scooter. As observed, the GC I and II and Gogo scooters were most unstable on higher slope surfaces (e.g., $6^{\circ}$ and $10^{\circ}$ ) in the forward and rearward directions. The results of static and dynamic stability tests are important to consider during the prescription process when trying to identify which mobility device is safer and how each responds to different terrains.

\section{Effectiveness of Brakes}

Overall, the Victory and GC II scooters were the fastest scooters to stop and the Gogo and GC I scooters were the slowest. The Victory scooters were the slowest to stop while driven in reverse, followed by the Gogo scooters. The Gogo scooters were fastest to stop on reverse command operations on the $10^{\circ}$ testing plane surface, followed by the GC II scooters. Note that the device braking distance is also important for clinicians to know during the prescription process, because the scooters do not have programmable controller options. Furthermore, the user's ability to control the scooter has to be considered, particularly when stopping responses differ among scooter models. Inability to control the scooter when it stops can cause harm not only to the user, but also to other people.

\section{Energy Consumption}

No significant differences were observed among the scooter models' energy consumption tests. The scooters in our study showed a theoretical range of $17.67-30.00 \mathrm{~km}$, similar to Pearlman et al. (2005), who found that low-cost electric powered wheelchairs (EPWs) had an energy consumption range of 17.2-32.3 km [14]. Based on these ranges, researchers suggested that the EPWs tested would run for more than 5 days without recharging the batteries when they were new [21]. The Gogo scooters had the lowest theoretical range, which should be kept in mind when considering prescription of this scooter model. When prescribing a scooter, clinicians should consider the user's lifestyle in order to select a scooter model based on its energy consumption capacity.

\section{Maximum Speed, Acceleration, and Retardation (Deceleration)}

Wheelchair-related injuries can be caused by several factors such as the environment, component designs, mobility device setup, and user ability to control a mobility device [18]. Maximum speeds were highest among the Victory and GC II scooters on most testing planes in the forward direction. The Gogo and GC I scooters showed the slowest maximum speed results in the forward direction. The Gogo scooters showed higher maximum speeds in the rearward direction on the horizontal plane than the other scooters. Even though we found a difference in maximum speed among the scooters, results ranges did not vary much between scooter models. Our study results present maximum speed because it is an important safety aspect to be considered, especially because the scooters' controllers cannot be programmed by clinicians. Therefore, the maximum speed cannot be preselected according to user need. If users cannot safely control the scooter at higher speeds, they might be at risk 
of not only hurting themselves but also other people. In addition, if users do not have good postural strength while driving the scooter and the scooter abruptly stops, they might be at high risk of being thrown out of the scooter.

Another safety concern with the scooters tested is their responses to reverse commands. Among the scooter models tested, the Gogo had the lowest braking distance during driving in reverse mode. In other words, the lower the retardation (deceleration) response, the faster the scooter will stop after a reverse command. Adverse responses of the scooter while driving in forward or reverse mode can affect user safety and, therefore, are an important issue to consider during a prescription process. Considering user safety, especially when driving in reverse conditions, caution should be taken when comparing these results with tiller tests results. Overall, not only did the Gogo and GC I scooters stop very quickly in reverse mode, but they also had the lower forces needed to break the tiller. Therefore, the user might be at risk of an accident when driving, particularly in reverse command, leading to a higher probability of breaking the tiller while driving the scooter. These two factors combined should be included during scooter selection to decrease the risk of accidents while driving a scooter in different directions.

\section{Climate Test}

The Gogo scooters and one GC I scooter failed the rain condition test and one GC II scooter failed the hot storage test. Mobility devices must be able to function in adverse weather conditions, whether it rains or snows. If a scooter cannot sustain 10 minutes under rain, users might be caught in the rain, with the potential of jeopardizing their health and safety. In addition to potential health problems, there is a possibility that the scooter will not function for at least 2 months after, and ultimately, the user's mobility will be compromised.

\section{Static, Impact, and Fatigue Tests}

As observed in the results, fatigue test results varied among scooter models. All Victory and GC I scooters passed the fatigue tests. All the Gogo scooters had motor failures and none reached even half of the 200,000 cycles on the double-drum test. These results suggest that the Gogo scooters do not meet minimum standards and are likely not durable enough to last 5 years of usage, which is the minimum number of years determined by Medicare to consider replacement of a mobility device. Durability and fatigue are important aspects to be considered when prescribing mobility devices, since these are strong indicators of expected reliability and also convey the relative value of the device. In the case of the Gogo, the nature of the failure suggests that a person may be stranded by the device. The GC II scooters did not pass the minimum number of 400,000 ECs (ECs $=151,662$ cycles). The variability of results observed between the GC II scooters is a serious concern, since this low durability could force a scooter replacement in less than 3 to 5 years of use. Moreover, it may jeopardize users' abilities to conduct daily activities safely and effectively. The variability in types of failure may be why the device life expectancy is so variable and unreliable - users may be at risk of receiving a scooter that will not meet their needs, will not last for 3-5 years and, in some extreme cases, may even cause injuries. Overall results of ECs and values (cycles per dollar) were higher in Victory and GC I scooters, which is a critical result suggesting significant cost benefits for the payers of these devices. On the other hand, the scooters with lower durability and lower value may result in insurance companies not replacing the scooter in less than 5 years or only paying for part replacements, resulting in a significant amount of paperwork to provide such replacements and a lengthy process for the user. The variability of EC results suggests that the life of scooters found on the market is still not as reliable as expected. When prescribing scooters, clinicians must consider durability and safety, as well as the lack of adjustability with these scooters, especially among users who have a progressive diagnosis. Our overall study results showed inconsistency among scooter models and manufacturers; in addition, they show evidence that the Gogo and GC II scooters do not meet the minimum criteria determined by ANSI/RESNA standards.

\section{Power and Control Systems}

Overall, we did not observe significant adverse responses from the Victory and Gogo power and control systems - only with the GC I and II. One concern was that if the user or someone else attempted to replace a battery, an electronic failure could happen and the scooter could stop working properly as a result of the wires having different colors than the standard allows. Another adverse and concerning response was found when the Gogo was being charged. If the user forgets the Gogo scooter is charging and starts driving it, her or she might 
pull the cord out from the wall, damage the scooter, and cause harm not only to him- or herself but also to someone who might be nearby. In addition to possible injury to the user and others, if a scooter starts moving while the battery is charging, the scooter may crash into objects or rip something out of the wall, resulting in the need for repairs or parts replacement.

\section{Tiller Test}

The tiller load testing helps convey the resistance of the tiller to structural collapse when forward-directed force is placed on the tiller. This could occur if the scooter is towed (e.g., if the battery dies) or if the scooter abruptly hits an obstacle and the user braces him- or herself to prevent falling. All scooters showed similar resistance to failure. The nature of most of the failures was the actual tiller structure collapsing as opposed to the adjustment mechanism.

Our study results suggest that at least some commercially available scooters may not meet the minimum standards required by Medicare and the VA. There is a need to improve the scooters found on the market to better serve the users. Mobility devices are tools to improve mobility, improve quality of life and, ultimately, improve performance in daily activities. Therefore, it is very important that the scooters' specifications and functions are reliable and that the scooter can be safely driven by the user.

It is important for clinicians and users to be aware that some scooters' responses to ANSI/RESNA tests were adverse and inconsistent. The design of scooters requires the user to have the ability to independently transfer in and out of the device, conduct independent weight shifts, and have sufficient upper-limb function to operate the scooter tiller steering mechanism. Some scooters allow the user to adjust the seat height, armrest width, and tiller distance from the seat and a few models have a power seat elevator; however, these options do not accommodate the user need for postural changes, for instance. The inability to adjust a scooter's seating system according to the users' needs would, in some cases, rule out a clinical recommendation of this mobility device because it would compromise user safety.

There is still a need for future studies investigating how scooters respond in real life situations. Our study was the first to investigate the reliability of some popular scooters currently provided by insurance companies. Qualitative studies investigating how scooters can truly benefit users, clinicians, and scooter manufacturers could be conducted to improve the quality of devices produced. Our study is just one step in the process of improving the quality and durability of the scooters available on the market.

The scooter manufacturers and models selected were those delivered by the VA healthcare system; some are also delivered through the Medicare system. Our intention was to provide quantitative results for how the models existing on the market truly respond under standard tests and what actual qualities or deficiencies they showed. Our main focus was, nevertheless, to provide quantitative information to clinicians, users, and health insurance companies on the importance of providing reliable scooters to avoid further injuries and potential replacement of devices after less than 3 to 5 years of usage.

\section{CONCLUSIONS}

Our study results showed inconsistent responses from scooter models within each standard test. This suggests that current models found on the market are not as reliable as they should be and therefore may be putting users at risk of injuries. The study results provided quantitative data that will not only benefit the quality of future scooters developed but will also help clinicians and users identify the appropriate device for a specific user. It is important for clinicians and users to be aware and understand the risks and benefits when looking for scooters in particular. With the industry trying to develop more affordable devices, there is a concern that DME is at risk of being low quality. For this reason, the study suggests that Medicare regulations be changed to include specific standard tests for scooters. Some scooters can support higher loads than the $100 \mathrm{~kg}$ standard, and in the future, scooters should be tested according to their maximum weight capacity. Suggestions for updating the standards would include testing the scooters with a dummy weight according to the maximum capacity of the mobility device.

Our study results indicate that the commercially available scooters tested were not as durable, reliable, and adjustable as they appeared to be and that they may not meet the minimum standard requirements. 


\section{ACKNOWLEDGMENTS}

\section{Author Contributions:}

Study concept and design: R. A. Cooper, J. L. Pearlman, R. Cooper, A. Kelleher.

Acquisition of data: A. E. Souza, B. Gebrosky.

Analysis and interpretation of data: A. E. Souza, R. A. Cooper,

J. L. Pearlman, R. Cooper, A. Kelleher, B. Gebrosky.

Drafting of manuscript: A. E. Souza, B. Gebrosky, J. L. Pearlman.

Critical revision of manuscript for important intellectual content:

R. A. Cooper, R. Cooper, A. Kelleher.

Statistical analysis: A. E. Souza, J. L. Pearlman.

Obtained funding: R. A. Cooper.

Administrative, technical, or material support: B. Gebrosky.

Study supervision: R. A. Cooper.

Competing Interest: The authors have declared that no competing interests exist.

Funding/Support: This material was based on work supported by the Center for Excellence for Wheelchairs and Associated with Rehabilitation Engineering-Human Engineering Research Laboratories, VA Pittsburgh Healthcare System (grant B6789C).

Disclaimer: The contents of this article do not represent the views of the VA or the U.S. Government.

\section{REFERENCES}

1. Administration on Aging. Aging statistics [Internet]. Washington (DC): Department of Health and Human Services; [updated 2013 May 8; cited 2011 Feb 7]. Available from: http://www.aoa.gov/AoARoot/Aging_Statistics/index.aspx

2. Karmarkar AM, Collins DM, Kelleher A, Cooper RA. Satisfaction related to wheelchair use in older adults in both nursing homes and community dwelling. Disabil Rehabil Assist Technol. 2009;4(5):337-43. [PMID:19565374] http://dx.doi.org/10.1080/17483100903038543

3. Wolff JL, Agree EM, Kasper JD. Wheelchairs, walkers, and canes: what does Medicare pay for, and who benefits? Health Aff (Millwood). 2005;24(4):1140-49.

[PMID:16012154]

http://dx.doi.org/10.1377/hlthaff.24.4.1140

4. Hubbard SL, Fitzgerald SG, Vogel B, Reker DM, Cooper RA, Boninger ML. Distribution and cost of wheelchairs and scooters provided by Veterans Health Administration. J Rehabil Res Dev. 2007;44(4):581-92. [PMID:18247255] http://dx.doi.org/10.1682/JRRD.2006.10.0136

5. Auger C, Demers L, Gélinas I, Jutai J, Fuhrer MJ, DeRuyter F. Powered mobility for middle-aged and older adults: systematic review of outcomes and appraisal of published evidence. Am J Phys Med Rehabil. 2008;87(8): 666-80. [PMID:18401265] http://dx.doi.org/10.1097/PHM.0b013e31816de163

6. LaPlante MP, Kaye HS. Demographics and trends in wheeled mobility equipment use and accessibility in the community. Assist Technol. 2010;22(1):3-17, quiz 19. [PMID:20402043]

http://dx.doi.org/10.1080/10400430903501413

7. Rentschler AJ, Cooper RA, Fitzgerald SG, Boninger ML, Guo S, Ammer WA, Vitek M, Algood D. Evaluation of selected electric-powered wheelchairs using the ANSI/ RESNA standards. Arch Phys Med Rehabil. 2004;85(4): 611-19. [PMID:15083438] http://dx.doi.org/10.1016/j.apmr.2003.06.023

8. Stogner J. The autonomy of the scooter. Make certain your clients get the right product. Rehab Manag. 2009;22(3):28-29. [PMID:19449772]

9. Cooper RA, Robertson RN, Lawrence B, Heil T, Albright SJ, VanSickle DP, Gonzalez J. Life-cycle analysis of depot versus rehabilitation manual wheelchairs. J Rehabil Res Dev. 1996;33(1):45-55. [PMID:8868417]

10. Hoenig H, Pieper C, Branch LG, Cohen HJ. Effect of motorized scooters on physical performance and mobility: a randomized clinical trial. Arch Phys Med Rehabil. 2007;88(3):279-86. [PMID:17321817] http://dx.doi.org/10.1016/j.apmr.2006.11.022

11. American National Standards Institute/Rehabilitation Engineering and Assistive Technology Society of North America. Wheelchair standards: Requirements and test methods for wheelchairs (including scooters). Vol 1. New York (NY): ANSI/RESNA; 1998.

12. American National Standards Institute/Rehabilitation Engineering and Assistive Technology Society of North America. Wheelchair standards: Additional requirements for wheelchairs (including scooters) with electrical systems. Vol 2. New York (NY): ANSI/RESNA; 1998.

13. McClure LA, Boninger ML, Oyster ML, Williams S, Houlihan B, Lieberman JA, Cooper RA. Wheelchair repairs, breakdown, and adverse consequences for people with traumatic spinal cord injury. Arch Phys Med Rehabil. 2009;90(12):2034-38. [PMID:19969165] http://dx.doi.org/10.1016/j.apmr.2009.07.020

14. Pearlman JL, Cooper RA, Karnawat J, Cooper R, Boninger ML. Evaluation of the safety and durability of low-cost nonprogrammable electric powered wheelchairs. Arch Phys Med Rehabil. 2005;86(12):2361-70.

[PMID:16344036] http://dx.doi.org/10.1016/j.apmr.2005.07.294

15. Cooper RA, Gonzalez J, Lawrence B, Renschler A, Boninger ML, VanSickle DP; American National Standards Institute-Rehabilitation Engineering and Assistive Technology Society of North America. Performance of selected lightweight wheelchairs on ANSI/RESNA tests. Arch Phys Med Rehabil. 1997;78(10):1138-44. [PMID:9339166] http://dx.doi.org/10.1016/S0003-9993(97)90141-6

16. Cooper RA, Boninger ML, Rentschler A. Evaluation of selected ultralight manual wheelchairs using ANSI/ 
RESNA standards. Arch Phys Med Rehabil. 1999;80(4): 462-67. [PMID:10206612] http://dx.doi.org/10.1016/S0003-9993(99)90287-3

17. Fitzgerald SG, Cooper RA, Boninger ML, Rentschler AJ. Comparison of fatigue life for 3 types of manual wheelchairs. Arch Phys Med Rehabil. 2001;82(10):1484-88. [PMID:11588758] http://dx.doi.org/10.1053/apmr.2001.26139

18. Kwarciak AM, Cooper RA, Ammer WA, Fitzgerald SG, Boninger ML, Cooper R. Fatigue testing of selected suspension manual wheelchairs using ANSI/RESNA standards. Arch Phys Med Rehabil. 2005;86(1):123-29.

[PMID:15641002] http://dx.doi.org/10.1016/j.apmr.2003.11.038

19. Liu HY, Cooper RA, Pearlman J, Cooper R, Connor S. Evaluation of titanium ultralight manual wheelchairs using ANSI/RESNA standards. J Rehabil Res Dev. 2008;45(9): 1251-67. [PMID:19319751] http://dx.doi.org/10.1682/JRRD.2007.12.0204

20. Karmarkar A, Cooper RA, Liu HY, Connor S, Puhlman J. Evaluation of pushrim-activated power-assisted wheelchairs using ANSI/RESNA standards. Arch Phys Med Rehabil. 2008;89(6):1191-98. [PMID:18503819] http://dx.doi.org/10.1016/j.apmr.2007.10.029

21. Cooper RA, VanSickle DP, Albright SJ, Stewart KJ, Flannery $\mathrm{M}$, Robertson RN. Power wheelchair range testing and energy consumption during fatigue testing. J Rehabil Res Dev. 1995;32(3):255-63. [PMID:8592297]

22. Cooper RA, Thorman T, Cooper R, Dvorznak MJ, Fitzgerald SG, Ammer W, Song-Feng G, Boninger ML. Driving characteristics of electric-powered wheelchair users: how far, fast, and often do people drive? Arch Phys Med Rehabil. 2002;83(2):250-55. [PMID:11833031] http://dx.doi.org/10.1053/apmr.2002.28020

23. Fass MV, Cooper RA, Fitzgerald SG, Schmeler M, Boninger ML, Algood SD, Ammer WA, Rentschler AJ, Duncan J. Durability, value, and reliability of selected electric powered wheelchairs. Arch Phys Med Rehabil. 2004;85(5): 805-14. [PMID:15129406] http://dx.doi.org/10.1016/j.apmr.2003.08.096

24. Cooper RA, Fitzgerald SG, Boninger ML, Prins K, Rentschler AJ, Arva J, O'connor TJ. Evaluation of a pushrim- activated, power-assisted wheelchair. Arch Phys Med Rehabil. 2001;82(5):702-8. [PMID:11346854]

http://dx.doi.org/10.1053/apmr.2001.20836

25. Liu HY, Pearlman J, Cooper R, Hong EK, Wang H, Salatin B, Cooper RA. Evaluation of aluminum ultralight rigid wheelchairs versus other ultralight wheelchairs using ANSI/RESNA standards. J Rehabil Res Dev. 2010;47(5): 441-55. [PMID:20803388] http://dx.doi.org/10.1682/JRRD.2009.08.0137

26. Rentschler AJ, Cooper RA. A comparison of the dynamics and static stability of power wheelchairs versus scooters. Proceedings of the 21st Annual IEEE/EMBS International Conference; 1999 Oct 13-16; Atlanta, GA. New York (NY): IEEE.

27. Centers for Medicare and Medicaid Services, U.S. Department of Health and Human Services. Centers for Medicare and Medicaid: Your guide to Medicare's Durable Medical Equipment, Prosthetics, Orthotics, and Supplies (DMEPOS) competitive bidding program [Internet]. Baltimore (MD): Centers for Medicare and Medicaid Services; [updated 2013 Jun; cited 2011 Feb 7]. Available from:

http://www.medicare.gov/Publications/Pubs/pdf/11461.pdf

28. Cooper RA. Wheelchair standards and testing. Wheelchair selection and configuration. New York (NY): Demos; 1998. p. $165-95$.

Submitted for publication March 22, 2011. Accepted in revised form January 23, 2013.

This article and any supplementary material should be cited as follows:

Souza AE, Pearlman JL, Cooper R, Kelleher A, Gebrosky B, Cooper RA. Evaluation of scooters using ANSI/RESNA standards. J Rehabil Res Dev. 2013;50(7): 1017-34.

http://dx.doi.org/10.1682/JRRD.2011.03.0054

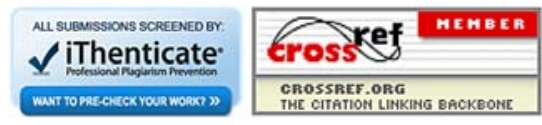


